\title{
Base isolation of heavy non-structural monolithic objects at the top of a masonry monumental construction
}

\author{
Andrea Chiozzi $(\bowtie)$, Michele Simoni, Antonio Tralli
}

Engineering Department, University of Ferrara

Via Saragat 1, 44122 - Ferrara, Italy

Phone: +393474027959

E-mail: andrea.chiozzi@unife.it

\begin{abstract}
The present paper deals with the relevant topic of seismic protection of heavy nonstructural monolithic objects, which are usually placed at the top of masonry monumental constructions for mainly decorative purposes, like pinnacles and heavy artwork. Even if, after seismic events, most of the losses are due to structural collapse of buildings and other structural systems, heavy non-structural objects of the kind considered in the present work represent a serious potential hazard for both human lives and cultural heritage. During earthquakes, such objects undergo large base accelerations, which may eventually cause their collapse by rocking and overturning. In the present contribution, the seismic protection of eleven ancient marble decorative pinnacles placed at the top of the three-arched masonry city gate in Ferrara (ITALY) is illustrated as a case study. In particular, a method for assessing the safety level of these systems under the action of seismic excitations is outlined and base isolation is proposed as a very promising technique for the seismic retrofit of heavy non-structural monolithic objects. The dynamical response to seismic actions of the underlying masonry construction is assessed through time-history dynamic analyses and the amplification of the ground accelerations at the base of the pinnacles is evaluated. Furthermore, the pinnacles are modeled as rigid bodies and their rocking behavior under base excitations is discussed. Finally, the effectiveness of the proposed base isolation system is assessed through non-linear dynamic numerical simulations.
\end{abstract}

Keywords Seismic Isolation, Masonry, Monolithic Objects, Non-structural Elements, Rigid Body, Nonlinear Dynamics 


\section{Introduction}

In the past, many research efforts have been devoted to the prevention of seismic damage of civil and industrial constructions, both modern and historical. Among the many aspects that are targeted in these studies, an increasing attention is being addressed towards the understanding of the seismic behavior of non-structural elements belonging to such constructions. The ultimate goal is to devise effective seismic protection systems for heavy artwork, sculptures, heavy decorative elements, pinnacles, merlons and similar objects which do not have a structural function but belong to world heritage and, in many cases, have an inestimable value; for an introduction to this subject the reader is addressed the works of McGavin (1981), Agbabian et al. (1988), Augusti and Ciampoli (1996), Vestroni and Di Cintio (2000), Roussis et al. (2008), Caliò and Marletta (2003), Contento and Di Egidio (2012).

The aim of the present paper is to illustrate the case study of the seismic protection through base isolation of eleven ancient marble pinnacles placed at the top of the three-arched masonry city gate in Ferrara, Italy, portrayed in Fig.1a, which underwent the 2012 Emilia seismic swarm.

Before analyzing the behavior of a non-structural object undergoing a prescribed seismic action, it is necessary to evaluate the amplification of the ground accelerations due to the presence of the underlying structure. Indeed, such structure is a deformable body and its response to dynamic actions depends on its geometric and material properties. In particular, the underlying structure produces an amplification of the ground accelerations which has to be quantified. Once the amplification effect has been evaluated, it is possible to assess the safety of the nonstructural monolithic objects placed at the top when undergoing the design seismic action.

From a mechanical point of view, in many cases, non-structural objects belonging to constructions are monolithic; therefore, they may be regarded as rigid bodies and their response to seismic loads may be analyzed through the methods of classical mechanics and specifically within the field of nonlinear dynamics of rigid bodies. The main phenomenon a rigid body undergo when subject to earthquake excitations is an oscillating motion around different instantaneous rotation centers belonging to its base known as rocking, which may eventually lead to collapse due to the final toppling of the whole body. 
In the study of pure rocking, a number of investigations have adopted a simple two-dimensional model, which was first proposed by Kimura and Iida (1934), later derived independently in a seminal paper by Housner (1963) and revised by Yim at al. (1980). The model is based on the assumption of no bouncing and sufficient friction to prevent sliding during impact. Although the model adequately represents pure rocking, it is found to be inadequate for the analysis of generalized behavior which includes slide rock and free flight; a more comprehensive two-dimensional model, which is applicable to the study of this generalized response, was proposed by Ishiyama (1982) and then by Shenton and Jones (1991a; 1991b) who in addition, for the first time investigated the case of rocking of rigid objects with an isolated base. Other variously enriched models for the rocking of rigid bodies has been proposed by Spanos and Koh (1984), Makris and Roussos (2000), Makris and Zhang (2001).

Recently, new interest has been devoted to the study of seismic protection of the artistic heritage and several authors addressed the problem of the rocking motion of rigid bodies provided with base isolation systems (Vestroni and Di Cintio 2000; Caliò and Marletta 2003; Di Egidio and Contento 2009, 2010; Vassiliou and Makris 2011) where the effectiveness of base isolation in increasing the safety level of art objects in case of earthquake has been assessed.

Finally, some three-dimensional models describing the dynamics of rigid bodies with impacts has been proposed in literature. In particular, the difficult problem of the three-dimensional motion of a an axisymmetric body rocking and rolling on a planar surface was addressed by Koh and Mustafa (1990), Magravanis et al. (2011) and Li et al. (2010). The full three-dimensional rocking motion of a prismatic rigid body has been investigated, among the others, by Konstantinidis and Makris (2007), Di Egidio et al. (2014).

Interestingly, full three-dimensional rocking of rigid objects is still an open research theme and many aspects of it (e.g. the spatial motion of axisymmetric rigid bodies resting with their flat base on a horizontal plane and subjected to arbitrary base accelerations) have still to be completely investigated.

The development of effective techniques for seismic risk mitigation of monolithic non-structural elements is a fundamental issue. A first approach (Lowry et al. 2006) consists in anchoring objects using different support mounts that essentially makes the object itself part of the structure. However, such a solution is 
not satisfying for it allows the transmission of large impulsive seismic forces which the object, being too brittle, may not be able to withstand. Furthermore, in this case the effects of the earthquake are usually not reversible.

An alternative approach consists in adopting base isolation systems (Di Sarno 2013; Bratosin 2008; Nastac and Leopa 2008) which has been demonstrated to be an excellent solution in limiting the transferred seismic actions thus effectively mitigating the seismic risk on different types of structures (Berto et al. 2013). Nevertheless, while base isolation for bridges or buildings has been largely developed in the last decades, base isolation for the comparatively much lighter artobjects and other kind of non-structural elements has not experienced the same level of development and it is still an open topic. As clearly pointed out in (Berto et al. 2013), even though the basic concepts which stand at the basis of base isolation systems are the same, the application of isolation techniques developed for civil structures to small objects requires more than a simple extension, and specific considerations are mandatory since the parameters governing the behavior of the seismic isolators need to be specifically calibrated. For an extensive survey of this topic, with an ample description of real world applications, the reader is addressed to the papers by Forni et al. (2003), Caliò and Marletta (2004) and Berto et al. (2012).

As initially stated, the present paper addresses the problem of the structural safety assessment and seismic protection of heavy monolithic objects placed at the top of a monumental construction through the illustration of a specific case study which concerns the seismic risk mitigation for eleven marble pinnacles placed at the top of a three-arched masonry city gate built in Ferrara (Fig.1a), Italy, at the end of Corso della Giovecca, between 1703 and 1704 a.C. The three-arched structure was realized based on a project signed by the italian architect Francesco Mazzarelli and fulfils the purpose of granting a full visual continuity along the whole principal avenue of the city which is made by the union of Viale Cavour and Corso della Giovecca and which represents the main urban arterial road. The marble pinnacles placed at the top of the gate have mainly a decorative purpose and their slenderness, coupled with their considerable mass, makes them highly vulnerable to seismic actions so that they cannot be considered safe. After the strong seismic events which struck Emilia in May 2012 and caused severe damage to the city's historical constructions, the pinnacles have been removed for safety reasons. In Fig. $1 \mathrm{~b}$ 
damages produced by a monolithic decorative non-structural element collapsed in Ferrara during 2012 Emilia earthquake is shown.

In the present work, the underlying masonry structure is analyzed and the amplification of the ground accelerations at the base of the pinnacles is evaluated. Then, the safety level of the pinnacles when subjected to seismic excitations is assessed and the conclusion that earthquake actions may set the pinnacles into a dangerous rocking motion which can eventually lead to overturning is drawn. Therefore, a specific base isolation system, based on the use of multiple double concave curved surface steel sliders, has been designed which is capable of preventing rocking motions and toppling of the monoliths and its effectiveness has been assessed.

The proposed base isolation technique has considerable innovative features in regard to present technology achievements in the field and was devised in cooperation with the Research and Development Department of FIP Industriale Group, a world leading company in the field of base isolation of structures.

The application discussed in the present paper, at the best of the authors' knowledge, is very peculiar and it is the first example in Italy of base isolation of heavy marble pinnacles on the top of an historic construction.

The paper is organized as follows. In Section 2 the underlying three-arched masonry city gate structure is characterized from a dynamical point of view. In Section 3 the rocking behavior of the single pinnacle subject to ground accelerations is assessed. In Section 4 the proposed base isolation systems is described and in Section 5 its effectiveness is established through numerical simulations. In Section 6 conclusions and future research direction are given.

\section{The Ferrara masonry city gate}

The case study considered in the present work is a three-arched masonry construction whose geometry is shown in Fig.2a. The structure is in good general condition and is made of clay artificial bricks and mortar. Eleven decorative marble pinnacles stand at the top of the gate.

Each pinnacle, whose geometry is portrayed in Fig.2b, is made of different axisymmetric marble blocks piled and bonded together by a central iron rod (the rod does not extend into the masonry structure beneath the pinnacle). A pinnacle 
may be regarded as an axisymmetric rigid body, which may undergo rocking motion when subjected to base excitations. As shown in Fig.2b, the pinnacle is 2.37 $\mathrm{m}$ tall and its circular base has a diameter $B$ of $0.60 \mathrm{~m}$. Marble is assumed to have a density $\rho$ of $2700 \mathrm{~kg} / \mathrm{m}^{3}$ and the resulting mass $M$ of the pinnacle is $980 \mathrm{~kg}$. Pinnacles are placed on two different orders; more precisely eight pinnacles are placed at an intermediate height of $9.80 \mathrm{~m}$ (hereinafter referred to as lateral pinnacles) and three pinnacles are placed on the top of the gate at a height of $18.50 \mathrm{~m}$ (hereinafter referred to as central pinnacles).

\subsection{The design seismic action}

Given the WGS84 coordinates for the city-gate location (44.832 N, 11.632 E), assuming a return period for the design seismic event of 712 years (i.e. corresponding to the ultimate limit state in terms of life safety for a Class III structure and soil category $\mathrm{C}$, in agreement with the Italian Building Code (NTC2008) the resulting design seismic action on the construction is determined. The corresponding design earthquake spectra is reported in Fig.3.

\subsection{Kinematic analysis (NTC2008)}

At first, it is necessary to assess the safety of the masonry structure itself undergoing the design seismic action, in order to rule out the possibility of collapse by formation of internal hinges and consequent local rigid body mechanisms. Both a linear and non-linear kinematic analysis following prescriptions contained in (NTC2008, par. §8.7.1) and the related explicative circular (CIRC2009, appendix C.8.A). For every possible local mechanism which is reckoned significant, the kinematic analysis develops through the following steps:

i) The structure, or part of it, is idealized into a labile system of rigid blocks, which are defined by specific crack planes (which can be assumed as a consequence of negligible masonry tensile strength). Rigid blocks can rotate or slide relative to each other, generating a local mechanism.

ii) The horizontal multiplier of the masses $\alpha_{0}$, which produces the activation of the considered mechanism, is evaluated in the initial reference 
configuration through the principle of virtual work. The multiplier has the dimensions of an acceleration $\left[\mathrm{L} / \mathrm{T}^{-1}\right]$.

iii) Linear kinematic analysis: from the horizontal multiplier of the masses computed in step ii) it is possible to determine the spectral acceleration $\alpha_{0}^{*}$ which activates the studied mechanism. To this aim, it is necessary to define the properties of a single degree-of-freedom (d.o.f.) equivalent oscillator. More precisely, the mass participant to the mechanism $M^{*}$ and the fraction of participant mass $e^{*}$ have to be defined. (CIRC2009) provides relations for the computation of $M^{*}, e^{*}$ and $\alpha_{0}^{*}$. The structural safety assessment is eventually carried out by comparing the spectral acceleration activating the selected mechanism $\alpha_{0}^{*}$ with the maximum design acceleration $a_{d}$ provided by (NTC2008) in terms of the design earthquake pseudo-acceleration spectrum and the behavior factor $q$ which, in the present study, can be considered equal to 2 (see NTC2008). If $\alpha_{0}^{*} \geq a_{d}$, the structure is safe in regards of the considered local mechanism.

iv) Nonlinear kinematic analysis: the structural safety assessment is carried out in terms of displacements, taking into account the fact that during the evolution of the collapse mechanism and before final failure occurs, the geometry of the system is being modified giving rise to the so-called geometric ductility. In a non-linear kinematic analysis the ultimate spectral displacement $d_{u}^{*}$ related to the considered mechanism has to be evaluated. To this aim, the horizontal multiplier of the masses $\alpha_{k}$ is computed for several different geometric configurations, which progressively describe the evolution of the mechanism and are characterized by the displacement $d_{k}$ of a selected control point of the system. In particular, the multiplier $\alpha_{k}$ will be zero for a certain value $d_{k, 0}$ of the displacement of the control point and a linear relation describing the dependance of $\alpha_{k}$ from $d_{k}$ will be obtained. Subsequently, it is necessary to determine the analogous linear relation for the single d.o.f. equivalent oscillator in terms of spectral acceleration $a^{*}$ and spectral displacement $d^{*}$ of the kind $a^{*}=a_{0}^{*}\left(1-d^{*} / d_{0}^{*}\right)$. (CIRC2009) provides relations for the computation of $a_{0}^{*}$ and the spectral displacements 
$d^{*}$ in terms of the displacements $d_{k}$ of the control point. According to (CIRC2009), the value of the ultimate spectral displacement $d_{u}^{*}$ is equal, for the considered application, to $40 \%$ of the spectral displacement $d_{0}^{*}$ for which spectral acceleration $a^{*}$ vanishes. The structural safety assessment is eventually carried out by comparing the previously determined ultimate spectral displacement $d_{u}^{*}$ (also called displacement capacity) with the displacement demand defined as the spectral displacement $S_{D e}\left(T_{s}\right)$ corresponding to the secant period $T_{s}=2 \pi \sqrt{d_{u}^{*} / a_{u}^{*}}$ where $a_{u}^{*}$ is the spectral acceleration corresponding to $d_{u}^{*}$ and $S_{D e}$ is the design earthquake pseudodisplacement spectrum provided by (NTC2008). If $d_{u}^{*} \geq S_{D e}\left(\mathrm{~T}_{s}\right)$, the structure is safe in regards to the considered local mechanism.

The kinematic analyses have been carried out with the software Mc4Loc (Mc4Software 2014). Twelve relevant in-plane mechanisms have been identified, six of which acting in the in-plane direction and six acting in the out-of-plane direction. The twelve local mechanism in the two principal directions have been represented in Fig.4.

All the mechanisms except the third in the out-of-plane direction (Fig.4i) result safe for both linear and non-linear kinematic analyses. Indeed, the third mechanism in the out-of-plane direction is the overturning mechanism of the single central pinnacle, which therefore cannot be considered safe under the design seismic action. For this mechanism numerical details of linear and non-linear kinematic analyses have been reported in Tab. 1. These results provide a first partial justification for a seismic retrofit intervention on the pinnacles.

\subsection{Vibration modes and natural frequencies}

In order to evaluate the fundamental period $T_{1}$ of the three-arched masonry structure and to establish its main vibration modes a linear finite element natural frequency analysis has been carried out using the finite element analysis software Straus7 (HSH 2014). The FEM model has been discretized with eight node bricktype finite elements and is shown in Fig.5a. Due to limited resources, material tests on masonry have not been done. In such cases, when analyzing existing 
constructions (NTC2008) imposes that mechanical properties of brick and mortar masonry have to be taken from Tab. C8A.2.1 of (CIRC2009). Such values have been summarized in Tab.2. From the analysis, three pure translational and a torsional mode have been obtained as the main four vibration modes which are represented in Fig.5b. Tab.2 contains frequency and participating mass in the inplane and out-of-plane directions for the four modes.

\section{Rocking behavior of the pinnacles}

In this section, the dynamic behavior of the marble pinnacles regarded as rigid bodies is assessed. In particular, their rocking behavior under base excitations is analyzed, in order to assess their structural safety with regard to collapse by toppling.

\subsection{Design seismic impulse at the base of the pinnacle}

In the following analysis an impulsive seismic excitation acting on the pinnacle is considered. In order to obtain the design earthquake impulse, it is necessary to evaluate, at least in a conventional way, the amplification effect of the underlying masonry construction (a more sophisticated analysis for the evaluation of the amplification effect will be presented in Section 4).

As shown in Tab. 2, the fundamental period of the structure $T_{1}$ results equal to 0.49 s. As suggested in paragraph C8A.4.2.3 of (CIRC2009), the design seismic acceleration acting on an object placed at a height $Z$ on a construction may be evaluated with the approximated formula:

$$
a_{d}=S_{e}\left(T_{1}\right) \cdot \Psi(Z) \cdot \gamma
$$

where $S_{e}\left(T_{1}\right)$ is the design earthquake spectra evaluated in $T_{1}, \Psi(Z)$ is the first normalized vibration mode of the structure and $\gamma$ is the corresponding participation factor. For an inverted triangular shape of the first mode, $\Psi(Z)$ can be evaluated with the formula $\Psi(Z)=\mathrm{Z} / \mathrm{H}$ where $\mathrm{H}$ is the maximum height of the construction.

For the case under study $S_{e}\left(T_{1}\right)$ is equal to $0.600 \mathrm{~g}$. When considering central pinnacles, $Z$ is equal to $18.25 \mathrm{~m}$ and $\Psi(Z)$ is equal to 1 whereas for lateral pinnacles 
$Z$ is equal to $9.80 \mathrm{~m}$ and $\Psi(Z)$ is equal to 0.537 . Finally, from the natural frequency analysis $\gamma$ is equal to 1.2 for central pinnacles and equal to 1 for lateral pinnacles.

From equation (1) the design seismic acceleration $a_{d}$ on central pinnacles results equal to $0.720 \mathrm{~g}$ whereas on lateral pinnacles of pinnacles is equal to $0.322 \mathrm{~g}$.

\subsection{Rocking motion of the pinnacles without isolation}

The problem of three-dimensional rocking of slender axisymmetric rigid bodies is still a very interesting open research theme and, to date, few results are available in literature. The two main contributions to the subject are given by Koh and Mustafa (1990) in the early nineties and by a recent work of Magravanis et al. (2011) on the rocking behavior of a conical frustum. As suggested in Magravanis et al. (2011), if one neglects imperfections which might break the symmetry, the problem of the three-dimensional axisymmetric body undergoing base accelerations acting in a fixed prescribed direction can be reduced to the much simpler problem of the two-dimensional rocking motion of a planar block (Housner, 1963; Yim et al. 1980).

Therefore, in the present paper, the rocking motion of the pinnacle is analyzed as a two-dimensional planar problem where the pinnacle is represented by one of its diametral sections as described in (Housner, 1963);

Let us assume that sliding between the pinnacle and its rigid base is prevented. In this case, in order to describe the two-dimensional rocking motion of the pinnacle under base excitations, a single Lagrangian parameter $\theta$ is needed. A possible choice for $\theta$ is the angle from the vertical as shown in Fig.6 where $G$ indicates the center of mass of the rigid body which is lying on the symmetry axis, at a height $z_{G}$ equal to $1.042 \mathrm{~m}$ above the base. Depending on the ground acceleration, the pinnacle may move rigidly with the ground or be set into rocking; in the letter case it will oscillate around the centers of rotation $O$ and $O^{\prime}$. Therefore, the problem is governed by two equation of motion which may be found in (Housner, 1963; Yim et al. 1980). $R$ represents the length of the segment connecting the center of mass $G$ to one of the rotation centers.

When subjected to base acceleration $\bar{a}_{g}$ in the horizontal direction the pinnacle will be set into a rocking motion when the overturning moment of the horizontal 
inertia force about one of the centers of rotation exceeds the stabilizing moment due to the weight of the body:

$$
\begin{aligned}
& M \bar{a}_{g} z_{G}>M g \frac{B}{2} \\
& \bar{a}_{g}>\frac{B}{2 z_{g}} g=0.208 g
\end{aligned}
$$

where $M$ is the mass of the pinnacle and $g$ is the acceleration of gravity. Equation (2) represents a necessary condition for the initiation of a rocking motion. For the present case-study, assuming $\bar{a}_{g}$ equal to the design seismic acceleration $a_{d}$ calculated in Subsection 3.1, condition (2) is satisfied for both central and lateral pinnacles. Nevertheless, this condition does not guarantee the continuation of the rocking motion. In order to assess if, after initiation, a rocking motion of the pinnacles is established, it is necessary to look more in depth into the phenomenon.

When the pinnacle is rotated through an angle $\theta$ and then released from rest with initial displacement, it will rotate about the center $O$ and it will fall back into the vertical position. If the impact is assumed to be inelastic, the rotation continues smoothly about the center $O^{\prime}$ and the moment of the momentum about $O^{\prime}$ is conserved. Thus:

$$
I_{0} i
$$

where $I_{0}$ represents the mass moment of inertia about $O$ or $O^{\prime}$ and $\delta=\tan ^{-1}\left(\mathrm{~B} / 2 \mathrm{z}_{G}\right)$. For the present case study, $I_{0}=1434 \mathrm{~kg} \cdot \mathrm{m}^{2}$. Dividing by $I_{0} i$ Eqn. (3) gives the ratio between angular velocities after and before impact:

$$
\frac{i}{i} \quad R B \sin \delta \text {. }
$$

If the ratio between angular velocities after and before impact is positive, then after impact the rotation of the pinnacle continues about the opposite center. If, conversely, angular velocity changes sign after impact the pinnacle bounces about the point of rotation prior to impact. Therefore, relationship (4) gives the following condition for the onset of a rocking motion:

$$
\frac{M R B \sin \delta}{I_{0}}<1
$$


which is satisfied for the pinnacle in our case study. Let us observe that condition (5) depends only on geometric and mass properties of the rigid body. This means that, according to the assumptions proposed in Housner (1963), whenever a rigid body for which condition (5) holds, gets tilted by an initial angle (e.g. in case of an external seismic excitation satisfying condition (2) like in our case) then, a rocking motion will be established. Conversely, if condition (5) does not hold, the block will bounce about the same corner and a proper rocking motion will not be established.

\subsection{Overturning by single-pulse excitations}

Dynamic behavior of rigid bodies under seismic actions is very complex and requires a time step integration of equations of motion in order to be fully described. Nevertheless, in order to assess the safety of pinnacles under dynamical conditions, useful information may be obtained from an analytical investigation of the collapse by overturning under single-pulse earthquake excitations.

In this subsection a simple overturning analysis for the pinnacles under singlepulse excitations is presented. At first, rectangular and half-sine pulses will be taken into consideration. Rectangular pulse is characterized by a constant acceleration $a_{g 0}$ lasting for a time $t_{1}$ whereas a half-cycle sine-wave pulse is characterized by an amplitude $a_{g 0}$ and duration $t_{1}$. In the present case-study, as seen in the previous section, the motion of central pinnacles is initiated by the base acceleration $a_{g 0}=a_{d}=0.720 \mathrm{~g}$. Even if the motion is initiated (i.e. condition (2) satisfied) and the body is subjected to rocking motion (i.e. condition (5) satisfied) the body may or may not overturn depending on the magnitude of $a_{g 0}$ and the duration $t_{1}$. Housner (1963) determined the duration $t_{1}$ of a rectangular pulse with acceleration $a_{g 0}$ required to overturn a slender block through the following equation:

$$
\cosh \sqrt{\frac{M g R}{I_{o}}} t_{1}=1+\left[1 /\left(2 \frac{a_{g 0}}{g \delta}\left(\frac{a_{g 0}}{g \delta}-1\right)\right)\right] .
$$

Analogously, for the half-cycle sine-wave pulse he derived the following equation relating the duration $t_{1}$ to the amplitude $a_{g 0}$ of the excitation: 


$$
\frac{a_{g 0}}{g \delta}=\sqrt{\left[1+\frac{I_{0}}{M g R}\left(\frac{\pi}{t_{1}}\right)^{2}\right]}
$$

Let us study the case of central pinnacles. Considering the geometrical and mass properties of the pinnacles and assuming $a_{g 0}=a_{d}=0.720 \mathrm{~g}$ equation (6) gives an overturning duration for the rectangular pulse excitation of $t_{1}=0.15 \mathrm{~s}$, while equation (7) gives an overturning duration for the sine-wave pulse excitation of $t_{1}=0.48 \mathrm{~s}$. As shown in (Gioncu and Mazzolani, 2010) typical pulse duration for earthquakes of low to medium intensity is between $0.10 \mathrm{~s}$ and $0.50 \mathrm{~s}$. This means that rectangular and half-sine pulse-type excitations, with the computed duration $t_{1}$ that brings to collapse the pinnacles by overturning, are typical of earthquakes that may occur in the Ferrara area. Moreover, it has to be pointed out that rectangular and half-sine pulses are not the most destructive type of pulses an earthquake is able to deliver.

Indeed, as shown in (Makris and Roussos 2000), a full-sine pulse of a given duration (also known as cycloidal pulse of type A) requires a considerably smaller acceleration amplitude to overturn a block compared to a rectangular or half-sine pulse of the same duration, due to the fact that ground decelerates during the second half of the pulse. For slender blocks, (Makris and Roussos 2000) give the following approximated equation relating the minimum overturning acceleration $a_{g 0}$ of a fullsine pulse to its duration and geometric parameters of the block:

$$
\frac{a_{g 0}}{g \delta} \approx 1+\frac{\omega_{p}}{6 p}
$$

where $\omega_{p}$ is the circular frequency and $p=\sqrt{3 g / 4 R}$. Assuming typical pulse durations of $0.10 \mathrm{~s}$ and $0.50 \mathrm{~s}$ as suggested in (Gioncu and Mazzolani, 2010), equation (8) gives the minimum overturning acceleration amplitude for the pinnacles $a_{g 0}$ respectively equal to $0.673 \mathrm{~g}$ and $0.249 \mathrm{~g}$ which is widely lower that the design acceleration $a_{d}=0.720 \mathrm{~g}$. In general, since equation (8) establishes a linear dependence between the minimum overturning acceleration amplitude $a_{g 0}$ of the pinnacle and the duration of the full-sine pulse $t_{1}$, it is easy to show that $a_{g 0}<a_{d}$ for every pulse duration $t_{1}>0.092 \mathrm{~s}$. Similar relations can be found in (Dimitrakopoulos and DeJong, 2012). 
Considerations reported in this Section corroborate the conclusion that pinnacles in our case-study are not safe under design seismic actions. For these reasons, a base isolation system has been designed in order to protect pinnacles from potential earthquake excitations.

\section{The isolation system}

This section contains a description of the base isolation system, which has been specifically devised for the protection of the pinnacles of the Ferrara city-gate.

\subsection{The isolation system}

Both lateral and central pinnacles are isolated through the use of double concave curved surface steel sliders. A schematic representation of the single isolator is depicted in Fig.7a. Two different isolating systems have been devised respectively for central pinnacles and lateral pinnacles.

For the three central pinnacles the isolating system for each pinnacle is made of three isolators placed at the vertex of a equilateral triangle and rigidly connected together by an upper steel plate on which the pinnacle lies. The system is schematically depicted in Fig.8a.

For each of the two groups of four lateral pinnacles the isolating system is made of four isolators (one beneath each pinnacle) connected together by a system of steel rods and plates which guarantees an approximatively zero relative displacement between isolators. In fact, the system may be regarded as a wide isolated base on which the four pinnacles lie. The system is schematically depicted in Fig. $8 \mathrm{~b}$.

Thus, for the isolation of all the eleven pinnacles seventeen isolators will be employed.

\subsection{Mechanical properties of the steel sliders}

According to producer specifications, the force-displacement behavior of the isolators is well represented by a rigid-plastic with hardening and friction response curve of the kind depicted in Fig. $7 \mathrm{~b}$, where $F_{0}$ is the maximum friction force which the isolator can develop, $K_{r}$ is the stiffness of the hardening branch, $F_{\max }$ is the 
maximum force which the isolator can develop at the end of the hardening branch. These quantities are defined by the following relations (Kelly 1993; Berto et al. 2013):

$$
\left\{\begin{array}{l}
F_{0}=\mu N_{S d} ; \\
K_{r}=\frac{N_{S d}}{R} ; \\
F_{\max }=F_{0}+K_{r} d ;
\end{array}\right.
$$

where $\mu$ is the friction coefficient along the sliding surface, $N_{S d}$ is the vertical load acting upon the isolator, $R$ is the equivalent curvature radius of the sliding surface and $d$ is the maximum allowed displacement. Furthermore, an equivalent damping coefficient $\xi_{e}$ can be defined through the following formula

$$
\xi_{e}=\frac{2}{\pi}\left(\frac{d}{\mu R}+1\right)^{-1}
$$

Friction coefficient $\mu$ is a function of the vertical load $N_{S d}$ and temperature. Therefore, the producer has not provided this value for the isolators used, but a range of values varying between $0.5 \%$ and $2.5 \%$. In the following analysis both these two values of $\mu$ have been taken into consideration.

Let us observe that each isolator in the isolation system for central pinnacles bears one third of the vertical load of each isolator in the isolation system for lateral pinnacles. In fact, in the former case each isolator bears one third of the weight of a single pinnacle while in the latter case each isolator bears the whole weight of a single pinnacle. Since mechanical parameters defined above depend on the vertical load, isolators in the two different isolation system will be characterized by different mechanical parameters. Nevertheless, for what concerns the single pinnacle (be it central or lateral) the whole isolation system has the same mechanical characteristics, for a single isolator bearing the whole pinnacle weight is equivalent to a system of three isolators each bearing one third of the weight of the pinnacle itself.

Tab. 3 summarize the mechanical properties for isolators used in the two isolation systems for the two different values of the friction coefficient. 


\section{$5 \quad$ Numerical simulations}

In order to assess the effectiveness of the isolation system in preventing rocking and overturning of the pinnacles, time-history dynamic analyses with a seismic accelerogram applied to the base of the isolated pinnacle have been carried out and are described in this Section.

\subsection{Design accelerograms and amplification effect}

In order to evaluate the dynamic response of the pinnacle, the definition of a design accelerogram is necessary.

As required by (NTC2008) and Eurocode 8 (EN1998), accelerograms compatible with earthquake design spectra must be selected in order to use timehistory dynamic analyses to assess the structural safety of the system. To this aim, a set of seven different accelerograms compatible with the earthquake design spectrum of the site, defined in (NTC2008) for an ultimate limit state in terms of collapse, has been generated with the software Rexel 3.5 starting from seven natural accelerograms and following prescriptions contained in (NTC2008). (NTC2008) prescribes that initial acceleragrams are scaled, so that the average of the spectral ordinates obtained for each scaled accelerogram must not differ from the elastic design earthquake spectrum of more than $10 \%$, in a range of periods which has to be chosen as the largest between $0,15 \mathrm{~s}-2 \mathrm{~s}$ and $0,15 \mathrm{~s}-2 \mathrm{~T}_{1} \mathrm{~s}$, where $\mathrm{T}_{1}$ is the fundamental period of the structure determined from a natural frequency analysis. Therefore, since periods of the principal vibration modes in both out-of-plane and in-plane directions (mode 1 and 3 respectively) are less than one, as shown in Tab. 2 , the range of periods chosen for the scaling of the ground motions is $0,15 \mathrm{~s}-2 \mathrm{~s}$ for both in- and out-of-plane directions. Consequently, for this particular structure, the scaling procedure is the same for both in-plane and out-of-plane directions and so are the resulting scaled accelerograms.

For each scaled accelerogram the corresponding spectrum (reported in Fig.9) can be generated.

In order to define the correct seismic action on the pinnacles, it is necessary to take into account the amplification effect due to the underlying masonry structure. Thus, for each spectrum compatible accelerogram, applied at the base of the structure as a forcing action, two different time-history dynamic analyses of the 
three-arched masonry city gate have been carried out using the finite element analysis software Straus7, one with the ground accelerations applied in the in-plane direction and one with the ground accelerations applied in the out-of-plane direction. Therefore, a total of fourteen analyses have been conducted.

The finite element model used is the same described in paragraph 2.3. Masonry has been modeled as a linear visco-elastic material with a Raleigh damping model. Rayleigh damping, also known as proportional damping, assumes that the global damping matrix $\mathbf{C}$ is a linear combination of the global stiffness $\mathbf{K}$ and mass $\mathbf{M}$ matrices:

$$
\mathbf{C}=\alpha \mathbf{M}+\beta \mathbf{K}
$$

where $\alpha$ and $\beta$ are constants of proportionality. The two constants $\alpha$ and $\beta$ are normally determined by using the following relationship

$$
\xi=\frac{1}{2}\left(\frac{\alpha}{\beta}+\beta \omega\right)
$$

for two values of the damping ratio $\xi_{1}$ and $\xi_{2}$ at two chosen frequencies $\omega_{1}$ and $\omega_{2}$ . Substituting the two sets of $\xi$ and $\omega$ values into (12) the following two equations for $\alpha$ and $\beta$ are obtained:

$$
\alpha=\frac{2 \omega_{1} \omega_{2}\left(\xi_{2} \omega_{1}-\xi_{1} \omega_{2}\right)}{\omega_{1}^{2}-\omega_{2}^{2}} ; \beta=\frac{2\left(\xi_{1} \omega_{1}-\xi_{2} \omega_{2}\right)}{\omega_{1}^{2}-\omega_{2}^{2}} .
$$

In the non-linear dynamic finite element analysis related to our case-study the values of $\alpha$ and $\beta$ for the Raleigh damping model where determined through equation (13) assuming for $\omega_{1}$ and $\omega_{2}$ the frequencies of the two principal modes (obtained through the natural frequency analysis) and for $\xi_{1}$ and $\xi_{2}$ the values 0.05 and 0.10 respectively, as suggested in (Peña et al. 2010) for masonry.

At the end of each time-history dynamic analysis the response of the structure in terms of acceleration at the base of both lateral and central pinnacles have been recorded. This response represents the design seismic accelerogram to be applied at base of the isolated pinnacles in order to assess the effectiveness of the isolation system. For the sake of simplicity, only the analysis for the accelerogram 378ya have been reported and discussed in the following, 
Fig.10a-b depict a comparison between the accelerogram 378ya applied at the ground level in the two main directions respectively and the corresponding accelerogram computed at the level of central pinnacles.

Fig.10c-d depict a comparison between the accelerogram 378ya applied at the ground level in the two main directions respectively and the corresponding accelerogram computed at the level of lateral pinnacles.

\subsection{Non-linear dynamic analysis of the isolated pinnacles}

In order to establish the seismic response of the isolated pinnacles and the effectiveness of the isolation system, time-history non-linear dynamic analyses with the amplified base accelerograms previously determined, have been conducted using the finite element software Straus7. Isolation system has been modeled as a parallel system of a spring and a damper, whereas the pinnacle has been modeled as a non-structural mass. Spring stiffness and damping coefficient for the damper are respectively $K_{r}$ and $\xi_{e}$ as defined in Tab. 3, considering both friction coefficients of $2.5 \%$ and $0.5 \%$.

Results in terms of acceleration response to the amplified ground accelerogram $378 y$ a for central pinnacles in both in-plane and out-of-plane directions are reported in Fig.11a-b respectively, for both friction coefficients, whereas results in terms of displacement response to the amplified ground accelerogram 378ya for central pinnacles are reported in Fig.11c-d respectively, for both friction coefficients.

Results in terms of acceleration response to the amplified ground accelerogram 378 ya for lateral pinnacles in both in-plane and out-of-plane directions are reported in Fig.12a-b respectively, for both friction coefficients, whereas results in terms of displacement response to the amplified ground accelerogram 378ya for lateral pinnacles are reported in Fig.12c-d respectively, for both friction coefficients.

As can be seen from the reported results, the maximum acceleration transferred to the pinnacles is, in every case, smaller than the minimum value required to initiate rocking motion defined by equation (2).

Finally, it is to be noticed that the maximum displacement which the pinnacle undergoes is, in every case, smaller than the maximum displacement allowed by the isolators, which is equal to $0.15 \mathrm{~m}$ (see Tab.3). 
Analogous results are obtained by applying each of the remaining six amplified spectrum compatible ground motions. In Tab 5 the entire set of results is summarized, for both in- and out-of-plane directions, in terms of maximum response acceleration and displacement values, which represents the main design parameters. Furthermore, mean and standard deviation have also been computed. From these results, the effectiveness of the isolation system devised for the protection of the marble pinnacles from seismic excitations has been assessed for each pinnacle.

\section{Conclusions}

This paper addressed the problem of seismic protection of heavy non-structural objects placed at the top of monumental masonry constructions though the illustration of the case study of the eleven marble monolithic pinnacles placed at the top of the three-arched masonry city gate in Ferrara. The underlying masonry structure has been characterized with a natural frequency finite element analysis and its safety against local mechanism has been assessed through kinematic analyses. Rocking motion and the safety against toppling of the pinnacles, regarded as rigid bodies under pulse-type earthquake excitations, have been discussed, showing that they are not safe under the design seismic action as defined by (NTC2008). A seismic isolation system for the prevention of rocking and overturning phenomena has been devised and its effectiveness has been established through non-linear dynamic analyses of the pinnacles under earthquake forcing action expressed through base accelerograms, which are spectrum compatible with the design seismic action. The amplification effect on the ground accelerations due to the underlying structure has been taken into account.

The non-linear dynamic analyses showed that the isolation system is effective in reducing seismic action transmitted to the pinnacles through the main structure, enough to prevent any rocking motion or overturning phenomena.

The problem deserves further investigation, for the actual rocking behavior of an axisymmetric rigid body under seismic actions is typically a three-dimensional problem whose effects have still to be fully understood. Furthermore, a more refined treatment of the underlying structure and in particular a more sophisticated 
evaluation of the damping coefficient for masonry will be dealt with in a further specific paper.

\section{Acknowledgements}

The Authors are grateful to the Municipality of Ferrara and Archt. N. Frasson for raising the interest and supporting the project. Authors are also grateful to Ing. M. G. Castellano, PhD of FIP Industriale Group for her kind support.

\section{References}

Agbabian M.S., Masri S.F., Nigbor R.L., Ginell W.S. (1988), Seismic damage mitigation concepts for art objects in museums. In: Proceedings of $9^{\text {th }}$ world conference on earthquake engineering, Tokyo-Kyoto, Japan.

Augusti G., Ciampoli M. (1996), Guidelines for protection of museum contents. In: Proceedings of $11^{\text {th }}$ world conference on earthquake engineering, Acapulco, Mexico.

Berto L., Favaretto T., Saetta A., Antonelli F., Lazzarini F. (2012), Assessment of seismic vulnerability of art objects: the "Galleria dei prigioni" sculptures at the Accademia Gallery in Florence. Journal of Cultural Heritage, Vol. 13, No. 1, pp. $7-21$.

Berto L., Favaretto T., Saetta A. (2013), Seismic risk mitigation technique for art objects: experimental evaluation and numerical modelling of double concave curved surface sliders. Bulletin of Earthquake Engineering, Vol. 11, pp. 1817-1840. Borisov A.V., Mamaev I.S., Kilin A.A. (2003), Dynamics of rolling disk. Regular and Chaotic Dynamics, Vol. 8, No. 2, pp. 201-212.

Bratosin D. (2008), Nonlinear effects in seismic base isolation. WSEAS transactions on applied and theoretical mechanics, Vol. 3, No. 4, pp. 133-144.

Caliò I., Marletta M. (2003), Passive control of the seismic rocking response of art objects. Engineering Structures, Vol. 25, pp. 1009-1018. 
Caliò I., Marletta M. (2004), On the mitigation of seismic risk of art objects: case studies. In: Proceedings of the $13^{\text {th }}$ World Conference on Earthquake Engineering, Vancouver, Canada.

CIRC2009, Circolare sulle "Nuove Norme tecniche per le costruzioni" di cui al D.M. 14/01/2008. S.O. n. 27, Gazzetta Ufficiale della Repubblica Italiana n. 47, 26/02/2009 (in Italian).

Contento A., Di Egidio A. (2012), Seismic protection of monolithic objects of art using a constrained oscillating base. In: Advances in Geotechnical Earthquake Engineering - Soil Liquefaction and Seismic Safety of Dams and Monuments, Edited by Abbas Moustafa, InTech.

Di Egidio A., Contento A. (2009), Base isolation of sliding-rocking non-symmetric rigid blocks subjected to impulsive and seismic excitations. Engineering Structures, Vol. 31, pp. 2723-2734.

Di Egidio A., Contento A. (2010), Seismic response of a non-symmetric rigid block on a constrained oscillating base. Engineering Structures, Vol. 32, pp. 3028-3039.

Di Egidio A., Zulli D., Contento A. (2014), Comparison between the seismic response of 2D and 3D models of rigid blocks. Earthquake Engineering and Engineering Vibration, Vol. 13, No. 1, pp. 151-162.

Di Sarno L., Base Isolation of Railway Bridges (2013). NAUN International Journal of Mechanics, Vol. 7, No. 3, pp. 302-309.

Forni M., Martelli A., Indirli M. (2003), Seismic isolation and other seismic vibrations control techniques of structures in Europe. In: Proceedings of the fourth International Conference on Earthquake Engineering and Seismology, Teheran, Iran.

Gioncu V., Mazzolani F. (2010), Earthquake engineering for structural design. CRC Press.

Housner G.W. (1963), The behavior of inverted pendulum structures during earthquakes. Bulletin of the Seismological Society of America, Vol. 53, No. 2, pp. 403-417.

HSH (2014), Straus7, Finite Element Analysis System. www.hsh.info. 
Ishiyama Y. (1992), Motions of rigid bodies and criteria for overturning by earthquake excitations. Earthquake Engineering and Structural Dynamics, Vol. 10, No. 5, pp. 635-650.

Kimura H., Iida K. (1934), On rocking of rectangular columns. Journal of the Seismological Society of Japan, Vol. 6, No. 3, pp. 125-149.

Kelly J.M. (1993), Earthquake resistant design with rubber. Springer-Verlag.

EN1998, Eurocode 8: Design of structures for earthquake resistance. European Committee for Standardisation TC250/SC8, 2003.

Koh A.S., Mustafa G. (1990), Free rocking of cylindrical structures. Journal of Engineering Mechanics. Vol. 116, pp. 34-54.

Konstantinidis D., Makris N. (2007), The dynamics of a rocking block in three dimensions. Proceedings of the Eigth HSTAM International Congress on Mechanics, Patras, Greece.

Li Y., Shi B. (2010), Response of 3D free axisymmetric rigid objects under seismic excitations. New Journal of Physics.

Lowry M., Armendariz D., Farra B.J., Podany J. (2006), Seismic mount making: a review of protection of objects in the J. Paul Getty museum from earthquake damage. In: Advances in the protection of museum collections from earthquake damage, symposium held at the J. Paul Getty museum at the Getty Villa, Malibu, United States.

Makris N., Roussos Y. (2000), Rocking response of rigid blocks under near-source ground motions. Géotechnique, Vol. 50, No. 3, pp. 243-262.

Magravanis A., Stefanou I., Vardoulakis I. (2011), Dynamic motion of a conical frustum over a rough horizontal surface. International Journal of Non-Linear Dynamics, Vol. 46, No. 1, pp. 114-124.

Makris N., Zhang J. (2001), Rocking response of anchored blocks under pulse-type motions. Journal of Engineering Mechanics, Vol. 127, pp. 484-493.

Mc4Software (2014), Mc4Loc, l'analisi dei meccanismi locali. www.mc4software.com (in Italian).

McGavin G.L. (1981), Earthquake protection of essential building equipment. John Wiley and Sons. 
Nastac S., Leopa A. (2008), New structural configurations for vibroisolation devices with high isolation performances. WSEAS transactions on applied and theoretical mechanics, Vol. 3, No. 5, pp. 155-164.

NTC2008, Norme Tecniche per le Costruzioni. Decreto Ministeriale 14/01/2008, S.O. n. 30 Gazzetta Ufficiale della Repubblica Italiana n. 29, 4/2/2008 (in Italian).

O’ Reilly O. M. (1996), The dynamics of rolling disks and sliding disks. Nonlinear dynamics, Vol. 10, p. 287-305.

Peña F., Lourenço P.B., Mendes N., Oliveira D. (2010). Numerical models for the seismic assessment of an old masonry tower. Engineering Structures, Vol. 32, pp. 1466-1478.

Roussis P.C., Pavlou E.A., Pisiara E.C. (2008), Base-isolation technology for earthquake protection of art objects. In: Proceedings of $14^{\text {th }}$ world conference on earthquake engineering, Beijing, China.

Shenton H.W., Jones N.P. (1991a), Base Excitation of Rigid Bodies. I: Formulation, Journal of Engineering Mechanics, Vol. 117, No. 10, pp. 2286-2306.

Shenton H.W., Jones N.P. (1991b), Base Excitation of Rigid Bodies. II: Periodic Slide-Rock Response. Journal of Engineering Mechanics, Vol. 117, No. 10, pp. 2307-2328.

Spanos P., Koh A. (1984), Rocking of rigid blocks due to harmonic shacking. Journal of Engineering Mechanics, Vol. 110, pp. 1627-1642.

Srinivasan M., Ruina A. (2008), Rocking and rolling: a can that appears to rock might actually roll. Physical Review E, Vol. 78, 06609.

Vassiliou M.F., Makris N. (2011), Analysis of the rocking response of rigid blocks standing free on a seismically isolated base. Engineering Structures, Vol. 41, No. 2, pp. 177-196.

Vestroni F., Di Cintio S. (2000), Base isolation for seismic protection of statues. In: Proceedings of $12^{\text {th }}$ world conference on earthquake engineering, Auckland, New Zealand.

Yim W.K., Chopra A.K., Penzien J. (1980), Rocking response of rigid blocks to earthquakes. Earthquake Engineering and Structural Dynamics, Vol. 8, No. 6, pp. $565-587$. 


\section{TABLES}

\begin{tabular}{|c|c|c|c|c|}
\hline $\begin{array}{c}\text { Single d.o.f. } \\
\text { equivalent oscillator } \\
\text { parameters }\end{array}$ & $\begin{array}{c}\text { Horizontal mass } \\
\text { multiplier activating } \\
\text { the mechanism }\end{array}$ & $\begin{array}{c}\text { Final displacement } \\
\text { before collapse }\end{array}$ & $\begin{array}{c}\text { Linear kinematic } \\
\text { analysis }\end{array}$ & $\begin{array}{c}\text { Non-linear kinematic } \\
\text { analysis }\end{array}$ \\
\cline { 1 - 1 }$M^{*}=1022 \mathrm{~kg}$ & \multirow{2}{*}{$\alpha_{0}=0.29 \mathrm{~m} / \mathrm{s}^{2}$} & $d_{k, 0}=0.641 \mathrm{~m}$ & $\alpha_{0}^{*}=2.082 \mathrm{~m} / \mathrm{s}^{2}$ & $d_{u}^{*}=0.091 \mathrm{~m}$ \\
\cline { 1 - 1 }$e^{*}=1$ & & $\alpha_{d}=3.092 \mathrm{~m} / \mathrm{s}^{2}$ & $S_{D e}\left(T_{s}\right)=0.119 \mathrm{~m}$ \\
\cline { 1 - 1 }$T_{s}=0.915 \mathrm{~s}$ & & NOT SATISFIED & NOT SATISFIED \\
\hline
\end{tabular}

Table 1 Numerical details of linear and non-linear kinematic analyses for mechanism depicted in

Fig. $4 \mathrm{i}$ involving one of the central pinnacles.

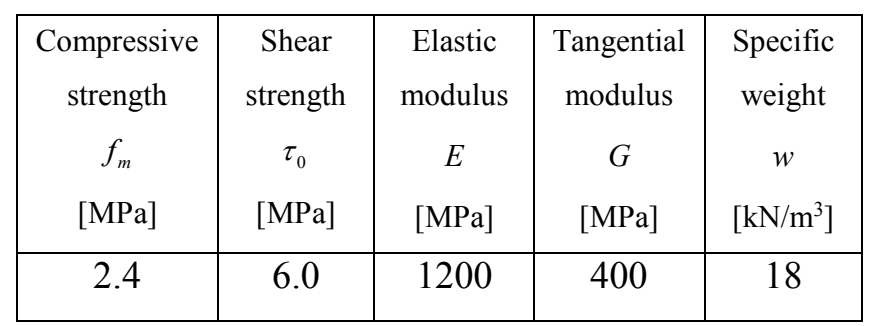

Table 2 Material parameters for masonry.

\begin{tabular}{|c|c|c|c|}
\hline Mode & $\begin{array}{c}\text { Frequency } \\
{[\mathrm{Hz}]}\end{array}$ & $\begin{array}{c}\text { Participating } \\
\text { mass in the in- } \\
\text { plane direction } \\
{[\%]}\end{array}$ & $\begin{array}{c}\text { Participating } \\
\text { mass in the } \\
\text { out-of-plane } \\
\text { direction [\%] }\end{array}$ \\
\hline 1 & 2.0131 & 0.00 & 54.54 \\
\hline 2 & 6.0679 & 0.01 & 0.00 \\
\hline 3 & 6.4394 & 87.96 & 0.00 \\
\hline 4 & 7.5946 & 0.00 & 26.44 \\
\hline
\end{tabular}

Table 3 Frequency and participating mass for the four vibration modes.

\begin{tabular}{|c|c|c|c|c|c|c|c|}
\hline \multirow{2}{*}{} & $N_{S d}$ & $\mathrm{~d}$ & $\mathrm{R}$ & $\xi_{e}$ & $F_{0}$ & $K_{r}$ & $F_{\max }$ \\
\cline { 2 - 8 } & {$[\mathrm{kN}]$} & {$[\mathrm{mm}]$} & {$[\mathrm{mm}]$} & {$[-]$} & {$[\mathrm{kN}]$} & {$[\mathrm{N} / \mathrm{mm}]$} & {$[\mathrm{kN}]$} \\
\hline$\mu=2.5 \%$ & 3.33 & 150 & 2000 & 0.16 & 0.083 & 1.665 & 0.333 \\
\hline$\mu=0.5 \%$ & 3.33 & 150 & 2000 & 0.04 & 0.016 & 1.665 & 0.266 \\
\hline
\end{tabular}

Table 4 Mechanical properties of the steel sliders isolation devices used. 


\section{FIGURES}

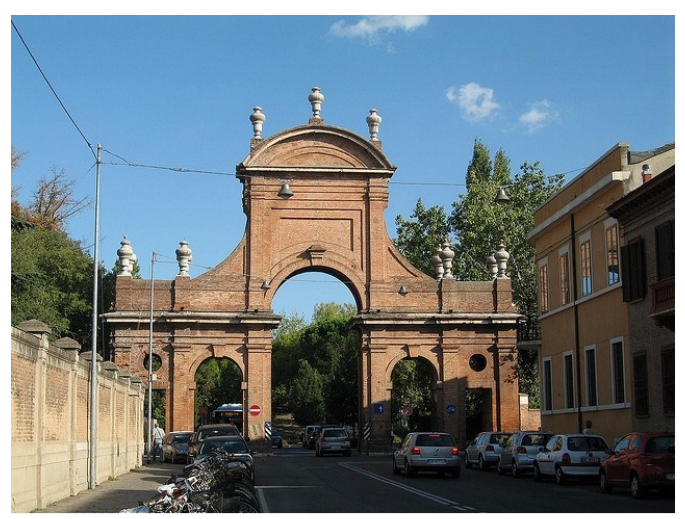

(a)

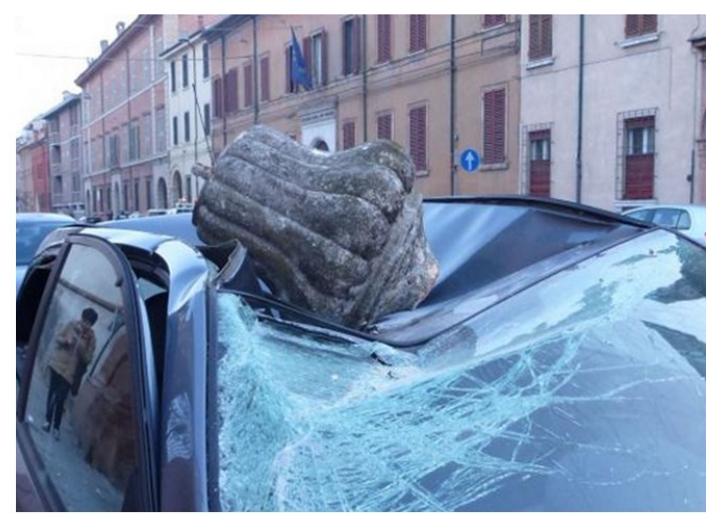

(b)

Fig.1 (a) Three-arched masonry city gate, Corso Giovecca, Ferrara, Italy; (b) damages from overturning of monolithic decorative elements during 2012 Emilia earthquake (Corso Giovecca, Ferrara, Italy).

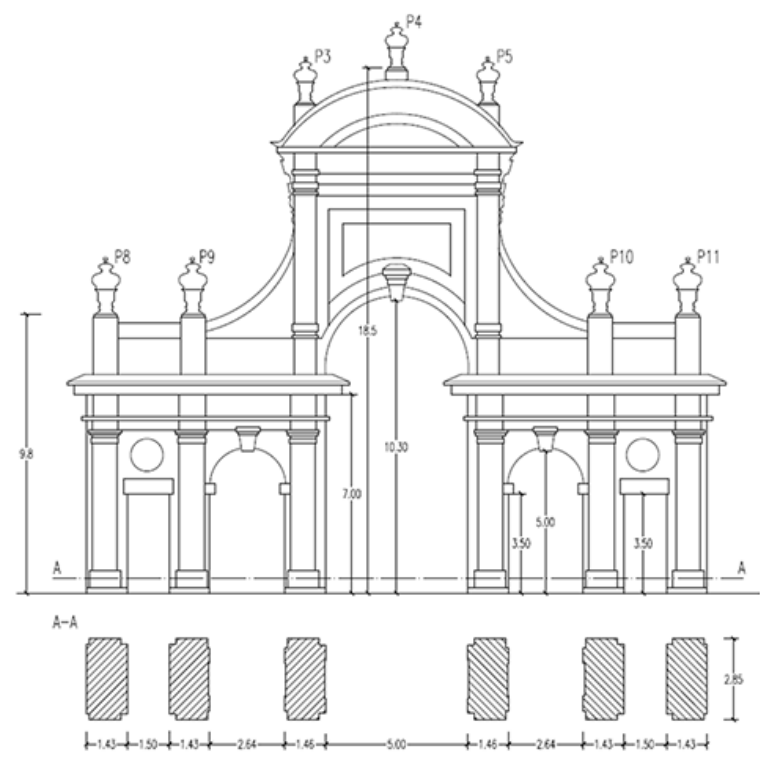

(a)

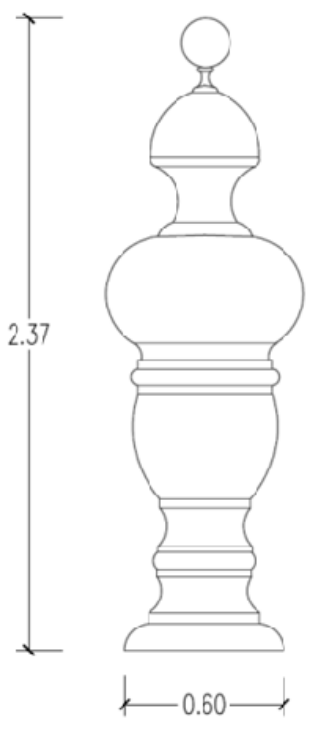

(b)

Fig.2 (a) Geometric representation of the three-arched masonry city gate; (b) Geometric representation of the pinnacle. 


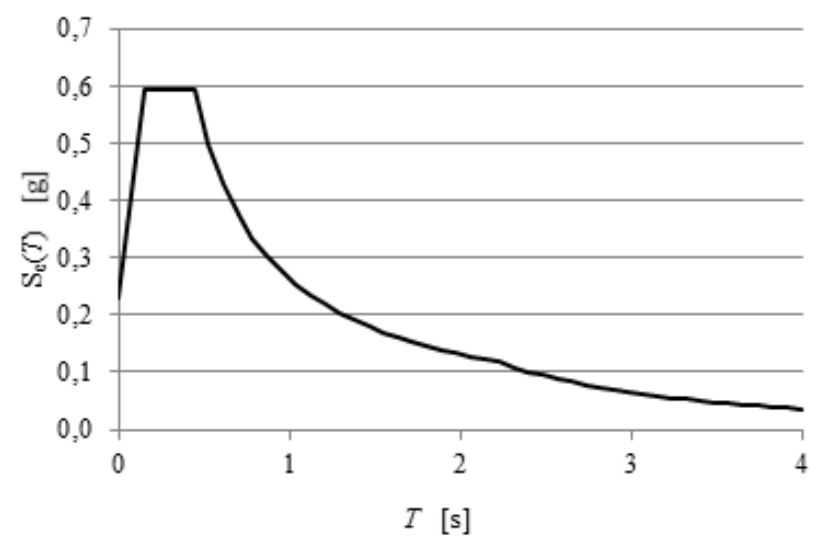

Fig.3 Design earthquake spectra for the three-arched masonry city gate according to NTC2008.

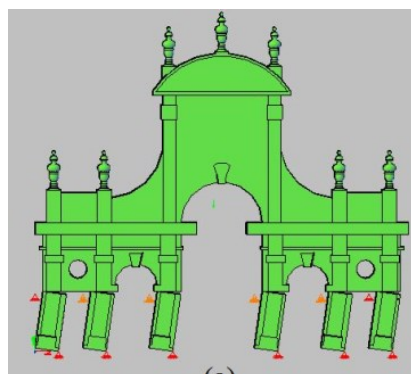

(a)

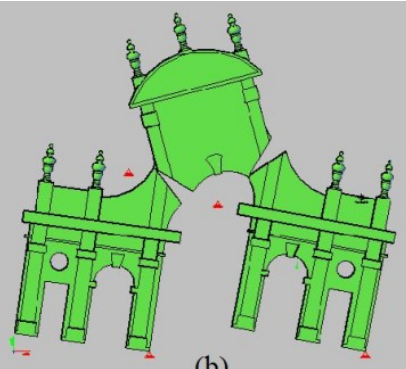

(b)

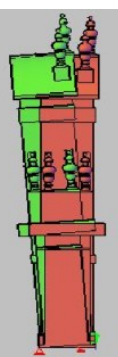

(g)

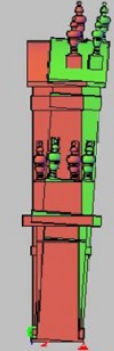

(h)

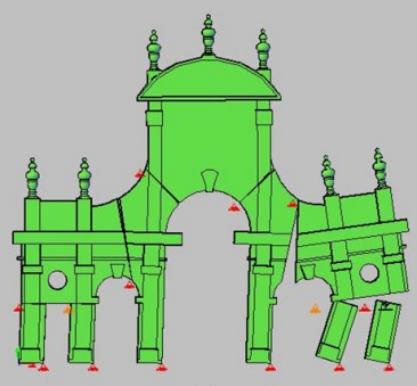

(c)

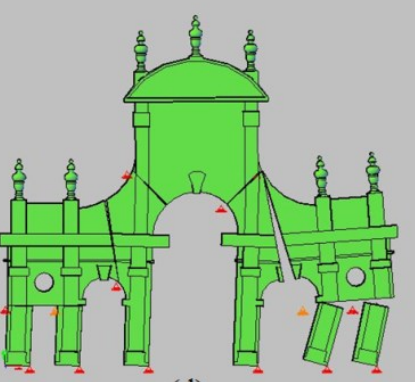

(d)

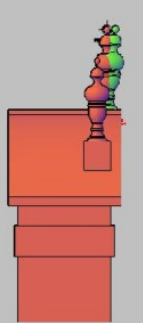

(i)

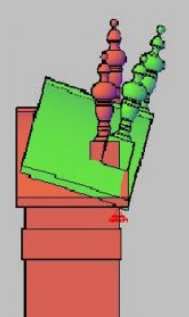

(1)

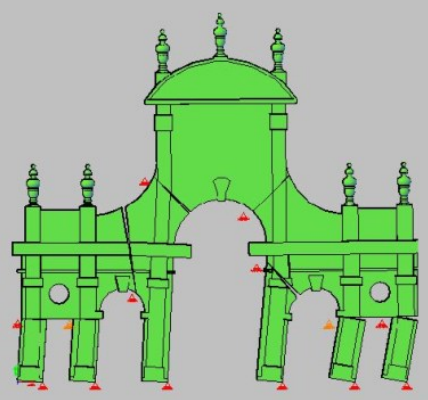

(e)

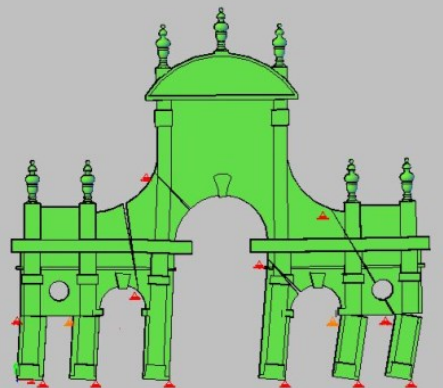

(f)

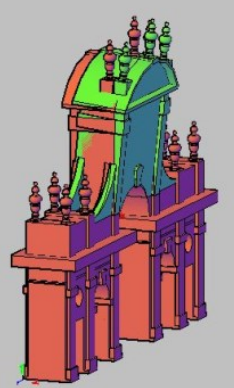

(m)

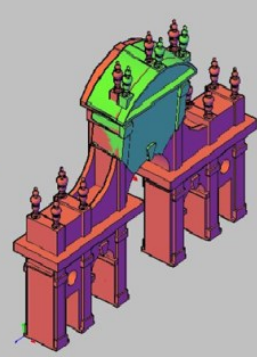

(n)

Fig.4 Six in-plane local mechanism for the masonry city gate (a)-(f); six out-of-plane local mechanism for the masonry city gate (g)-(n). 


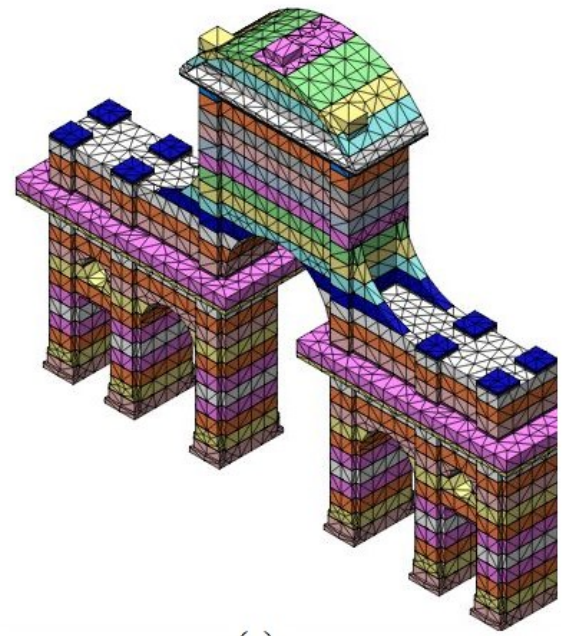

(a)
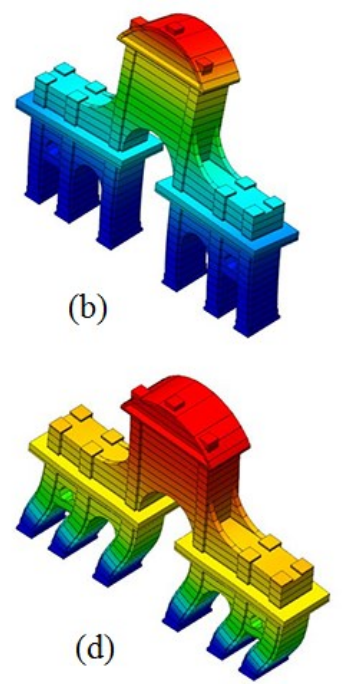
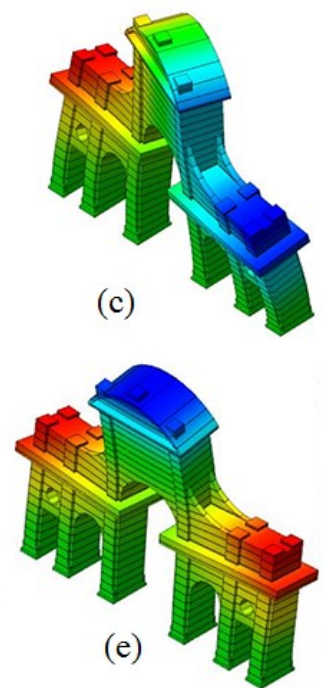

Fig.5 (a) Finite element model of the three-arched masonry city gate for natural frequency analysis; the first four vibration modes: (b) translational mode in the out-of-plane direction, (c) torsional mode, (d) translational mode in the in-plane direction, (e) partial translational model in the out-ofplane direction.

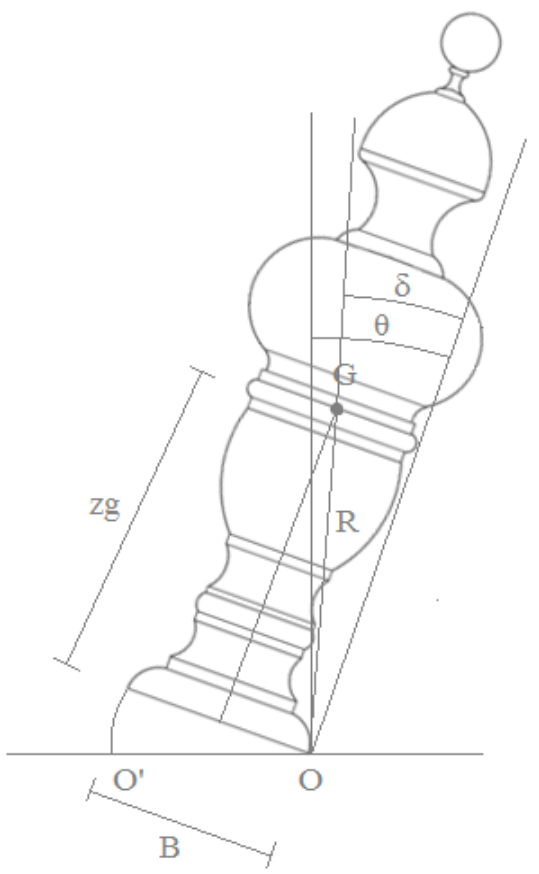

Fig.6 Rocking pinnacle. 


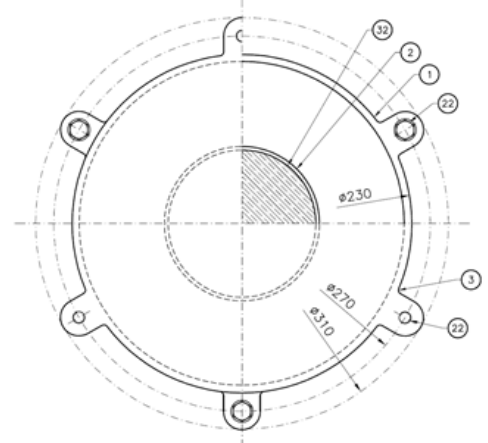

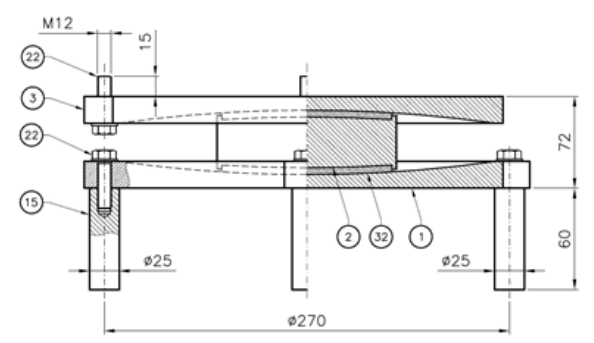

(a)

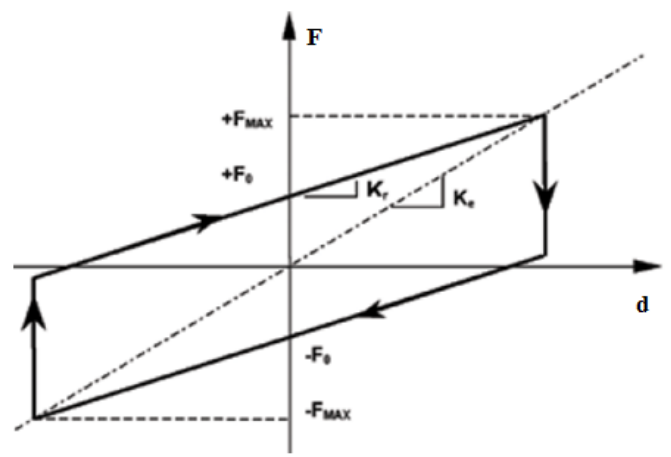

(b)

Fig.7 (a) Schematic view of the seismic isolator: a double concave curved surface steel slider developed and produced by the Research and Development Department of FIP Industriale Group; (b) force-displacement response of the isolator.

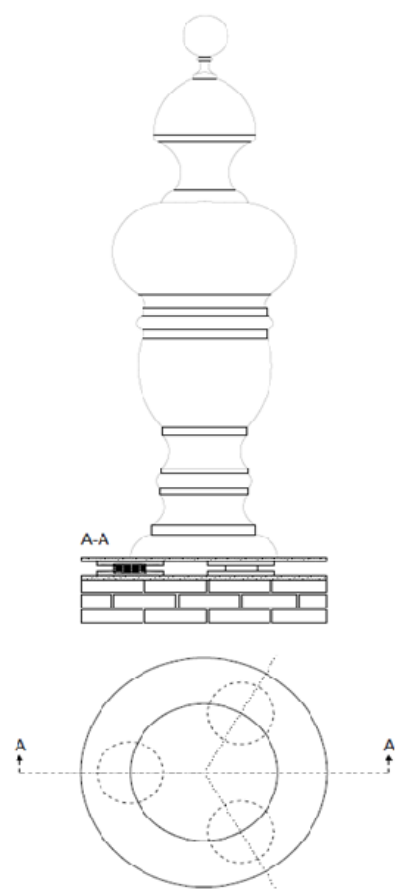

(a)

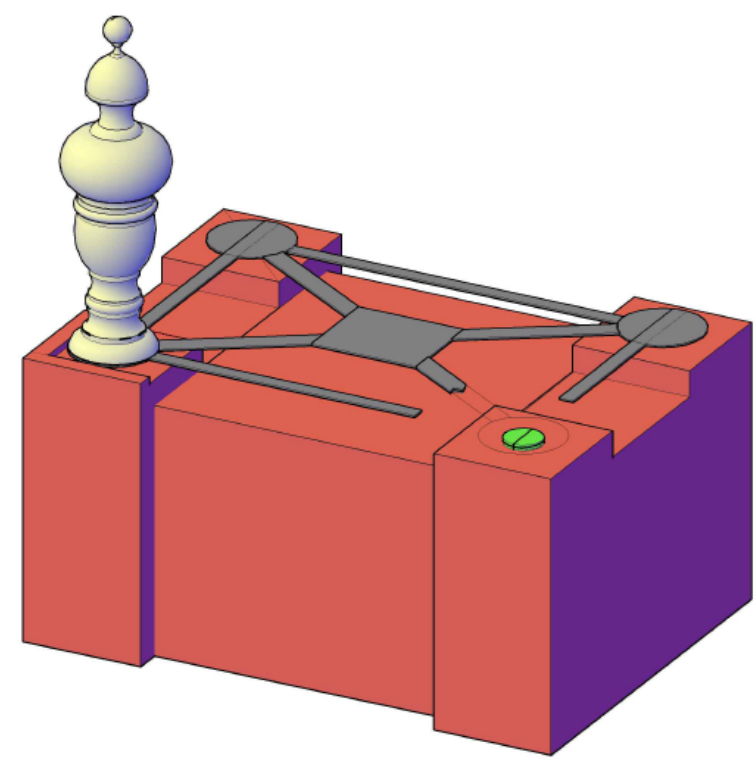

(b)

Fig.8 Isolating system devised for central pinnacles (a), and lateral pinnacles (b). 


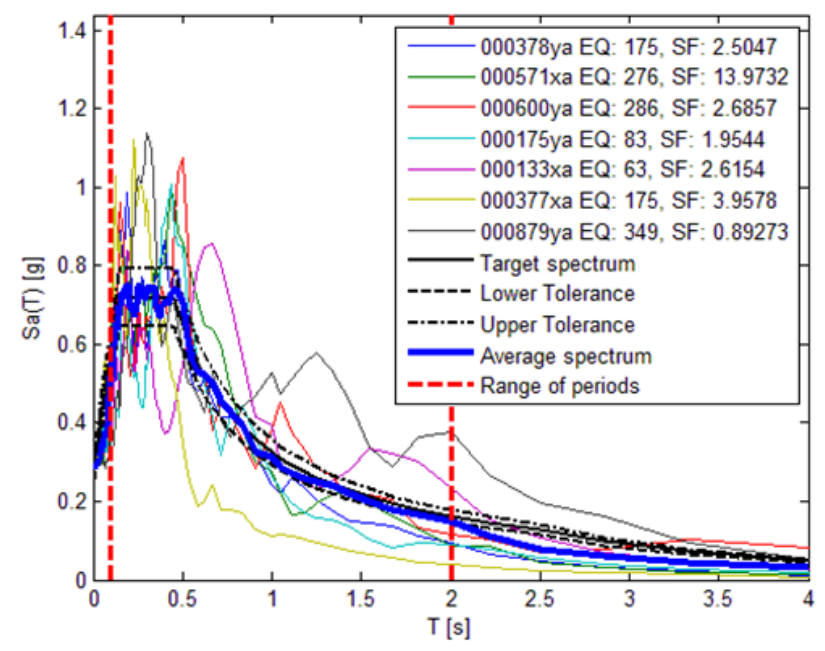

Fig.9 Earthquake spectra compatible with the design spectra defined by NTC2008 generated with Rexel 3.5.

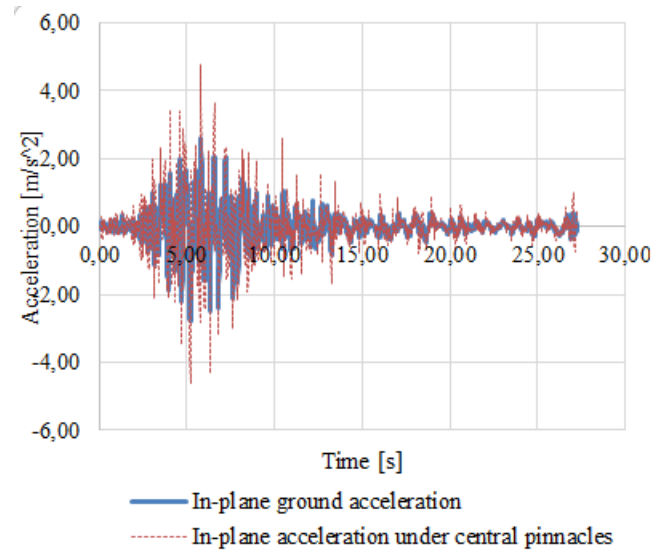

(a)

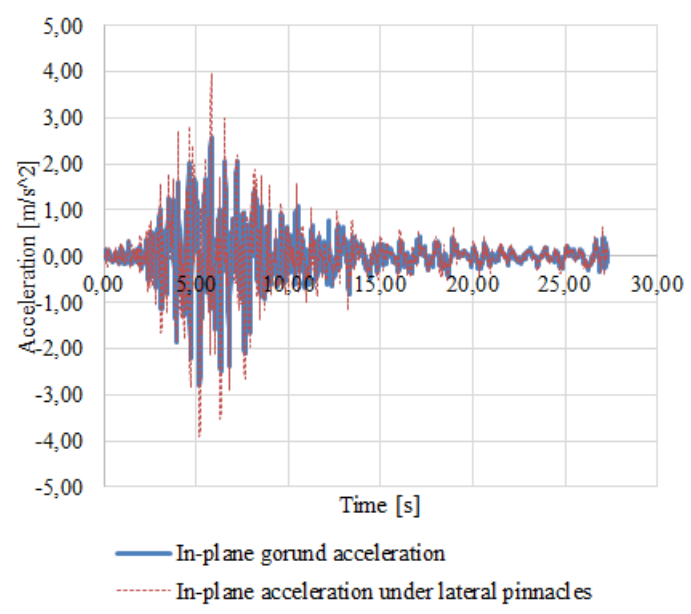

(c)

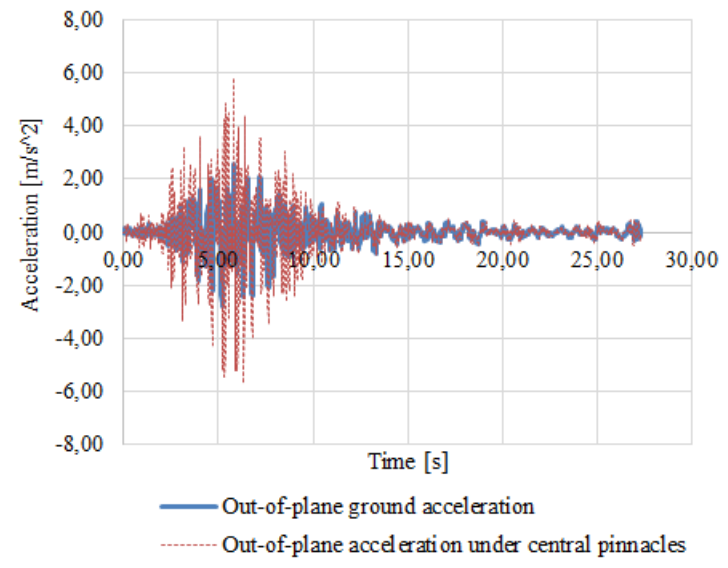

(b)

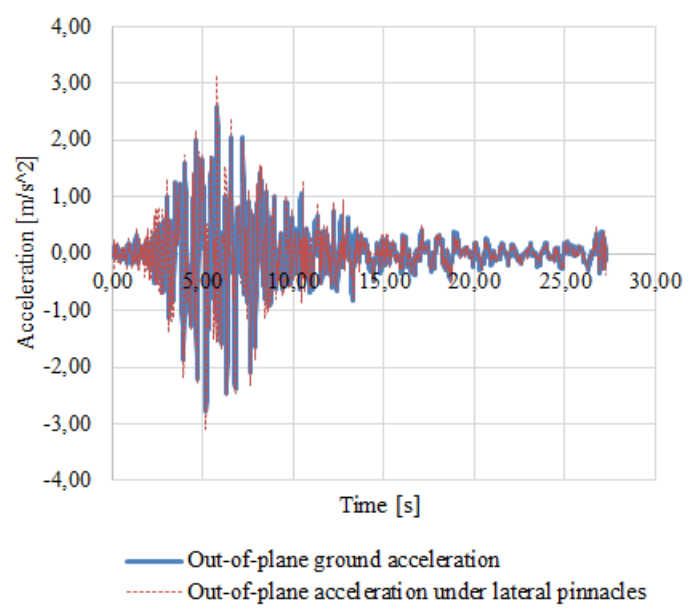

(d)

Fig. 10 Amplification of the base seismic action 378ya due to the masonry structure on central pinnacles in the in-plane (a) and out-of-plane (b) directions and on lateral pinnacles in the in-plane (c) and out-of-plane (d) directions. 


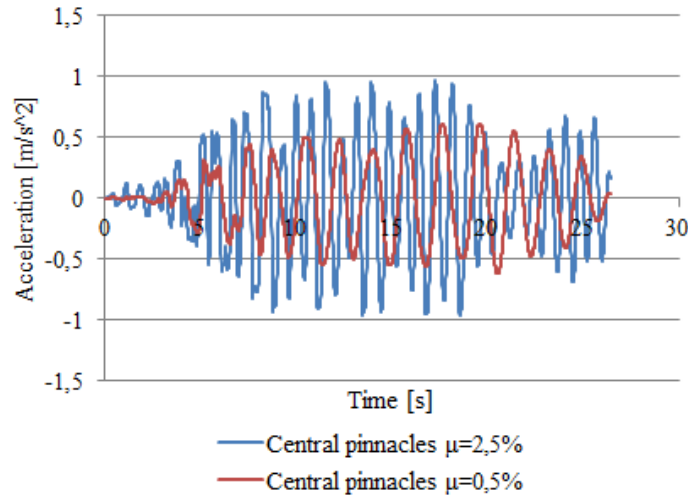

(a)

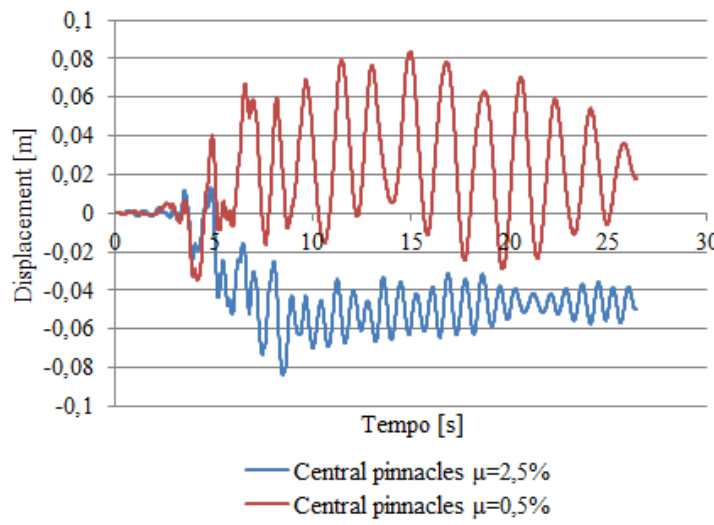

(c)

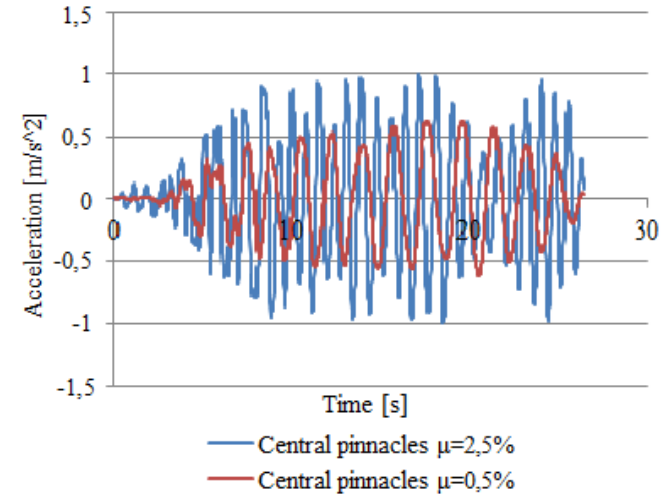

(b)

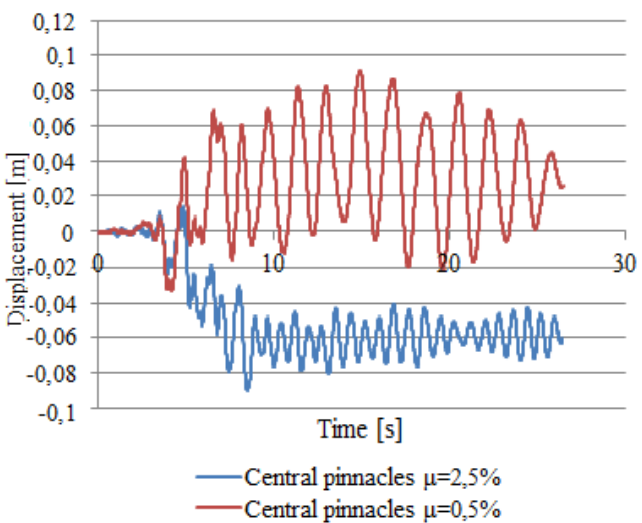

(d)

Fig.11 Response of central pinnacles to the seismic action defined by (amplified) accelerogram $378 y$ ya in terms of in-plane (a) and out-of-plane (b) acceleration, in-plane (c) and out-of-plane (d) displacements. 


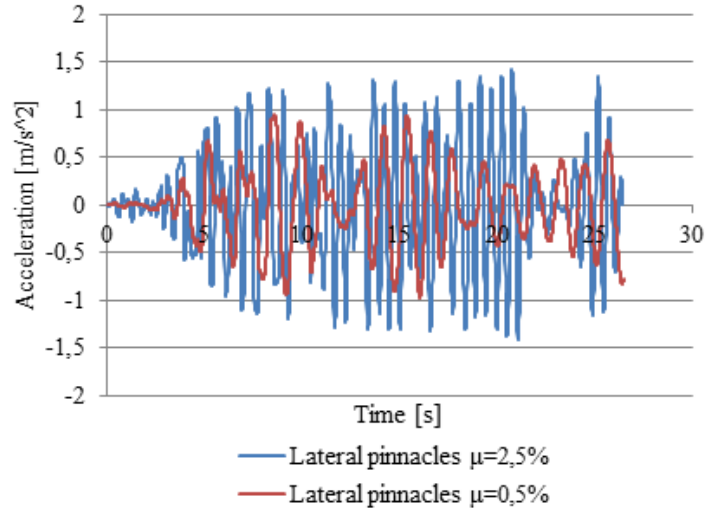

(a)

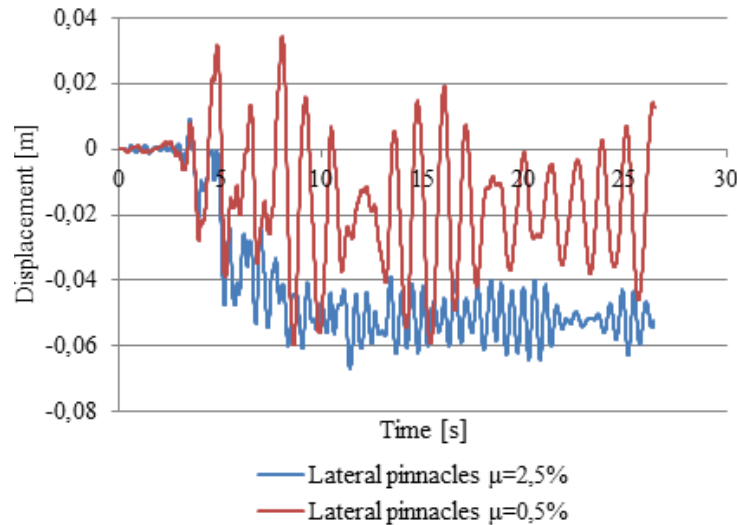

(c)

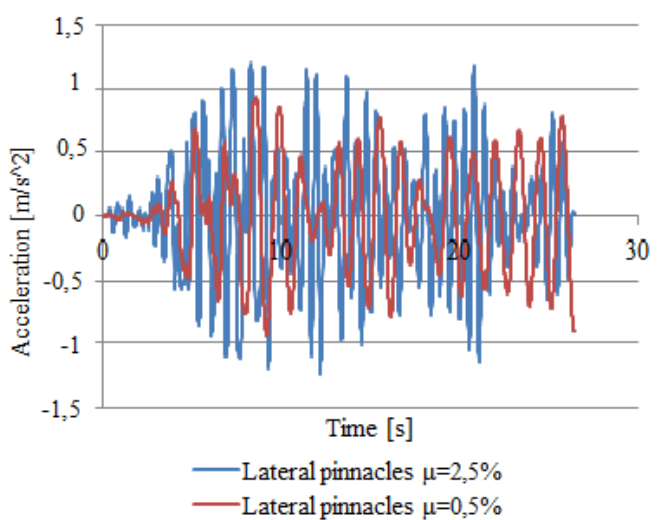

(b)

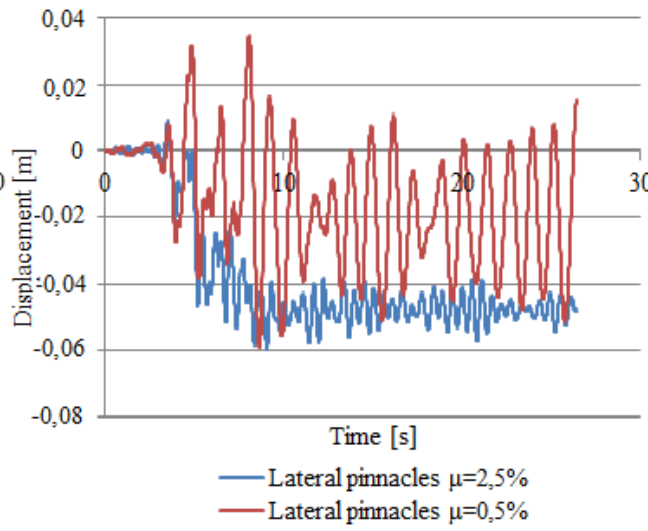

(d)

Fig.12 Response of lateral pinnacles to the seismic action defined by (amplified) accelerogram 378 ya in terms of in-plane (a) and out-of-plane (b) acceleration, in-plane (c) and out-of-plane (d) displacements. 